\title{
Identifying an Appropriate Forecasting Technique for Predicting Future Demand: A Case Study on a Private University of Bangladesh
}

\author{
Sayma Suraiya $^{1}$ and M. Babul Hasan ${ }^{* 2}$ \\ ${ }^{1}$ Department of General Educational Development, Daffodil International University, Dhanmondi, Dhaka-1207, Bangladesh \\ ${ }^{2}$ Department of Mathematics, Dhaka University, Dhaka-1000, Bangladesh
}

( Received: 22 May 2017 ; Accepted : 16 January 2018)

\begin{abstract}
Demand forecasting and inventory control of printing paper is crucial that is frequently used every day for the different purposes in all sectors of educational area especially in Universities. A case study is conducted in a University store house to collect all historical demand data of printing papers for last 6 years (18 trimesters), from January (Spring) 2011 to December (Fall) 2016. We will use the different models of time series forecasting which always offers a steady base-level forecast and is good at handling regular demand patterns. The aim of the research paper is to find out the less and best error free forecasting techniques for the demand of printing paper for a particular time being by using the quantitative forecasting or time series forecasting models like weighted moving average, 3-point single moving average, 3-point double moving average, 5-point moving average, exponential smoothing, regression analysis/linear trend, Holt's method and Winter's method. According to the forecasting error measurement, we will observe in this research that the best forecasting technique is linear trend model. By using the quantities of data and drawing the conclusion with an acceptable accuracy, our analysis will help the university to decide how much inventory is absolutely needed for the planning horizon.
\end{abstract}

Keywords: Demand forecast, inventory, time series analysis, error measurement.

\section{Introduction}

In modern business arena which is enough for now is not enough for couple of seconds later as the data and the information is changing with the passage of time rapidly. But people are not stand still to think for a second if they make a forecast for the future what will be the result? Anyway, forecasting is the process of making predictions of the future based on past and present data and commonly by analysis of trends.

Demand forecasting is predicting future demand for the product. In other words, it states to the prediction of probable demand for a product or a service on the basis of the past events and dominant trends in the present. Demand forecasting plays a significant role in basic Operations Management as an input for planning activities and is used in wide range from the inventory management, shipping, distribution, reclamation, repair and maintenance to the coordination of suppliers and operations of many works $\left(\right.$ Fildes et $\left.\mathrm{al}^{8}\right)$. Poor forecasting effects stock outs or high inventory. Inventory forecasting methods are critical elements of the forecasting process as accuracy can drastically effect on business profitability. It is becoming gradually important and necessary for business to predict their future demand in terms of inventory availability, sales assumptions, costs and profits.

Modern inventory planning systems perform a statistical analysis of historical item usage patterns to predict future usage. Some also employ demand-sensing techniques using real-time data in addition to some historic demand. After calculating a new forecast, the systems determine optimal stocking levels. On a day-to-day basis, they compare actual inventory status with optimal stocking levels to decide what to order and when. Thus, forecasts are a fundamental piece of inventory planning. Item demand history is usually taken from actual sales or item order or shipping data. For inventory planning, forecasting usually deals with a time series of monthly or weekly data. The Inventory Forecasting system assists the enterprise to look at past sales/ use and matches the algorithm which would have had the best chance of success in estimating previous sales. That algorithm is then used to predict future sales/use. Businessmen always think to use their resources optimum in order to minimize their costs as there is a statement "Minimize your Cost and Maximize your Profit'. Thus it is very important to prepare the strategic plans which are all most to the actual happening. On the other hand businessman makes the plan for the future not for the present and that's why they need to think effectively to manage the cost of the inventory, technology, skilled human resources, labor, time, and financial resources in the best way and to avoid wastage.

According to Bowersox, Closs and Copper ${ }^{1}$, inventory management of any business organization play an important role in many aspects. Inventory management enables the business organizations to select the economies of scale which is a unique weapon for reducing the production cost. Proper inventory management helps the business organizations to make a balance between the supply of raw materials, amount of inventory in the store and the demand of the finished products. Muzumdar and Fontanella ${ }^{6}$ highlighted the consequence of inventory in their research. It is difficult to make reliable prediction for the required inventory. There is vice versa impact for the limited and excessive inventory stock or level.

Chopra and $\mathrm{Meindl}^{2}$ suggested that forecast errors must be analyzed properly because it contains important information. Ritzman \& King ${ }^{9}$, Wacker and Lummus ${ }^{11}$ observed in their article that an inaccurate forecast creates difficulties in making decisions of purchasing, financing and scheduling. Markridakis ${ }^{4}$ put emphasis on combining different forecasting methods to improve forecast accuracy. Chopra and Meindl $^{2}$ introduced simulation based forecasting method to identify future demand by analyzing historical data.

Based on the above literature review, we observe that if a 
well suited demand forecasting method can be implemented for any company then their inventory level can be improved for the benefit of the business.

In our study, we will work with such stationary of Daffodil International University (DIU) like printing paper that is very mandatory of any educational institute. Prediction of proper future demand of this product can minimize storage cost as well as optimize order quantity. Our paper will investigate the error in different inventory demand forecasting methods. We will also find out how the error influences the actual forecasting in total inventory at the end of the year and find out the best method by analyzing the error among eight methods. It will be the first comprehensive study of demand forecasting in inventory level in Bangladesh and which will help to the next researcher for further depth investigation.

The rest of the paper is organized as follows. In Section 2, we have discussed about the existing forecasting techniques. In Section 3, we will analyze the problem and data collection. Then present the data graphically in Section 4. In section 5, we will make a conclusion among different forecasting techniques by making an error measurement table.

\section{Existing Forecasting Techniques}

In this section, we will discuss the existing forecasting techniques which are relevant to our research.

n-period single moving average. The result that we get after add up the first $\mathrm{n}$ (i.e. 3/5) numbers from the list and divide the answer by $\mathrm{n}$ is called the $\mathrm{n}(3 / 5)$ period single moving average, it will be repeating until we reach the last $n$ numbers.

\section{Double Moving Average (DMA).}

The double exponential moving average (DEMA) provides a solution by calculating a faster averaging methodology. In technical analysis, the term moving average refers to an average of price for a particular trading instrument over a specified time period.

Double moving average of $\mathrm{n}$ periods is defined as follows.

Weighted Moving Average. A Weighted Moving Average (WMA) assigns a weighting factor to each value in the data series according to its age. The most recent data gets the greatest weight and each price value gets a smaller weight as we count backward in the series. They are widely used where repeated forecasts required-uses methods like sumof-the-digits and trend adjustment methods. The Weighted Moving Averages is defined as follows.

$\operatorname{MA~}(3)=w_{1} \cdot D_{t}+w_{2} \cdot D_{t-1}+w_{3} \cdot D_{t-2}$

Exponential Smoothing Techniques. Simplest of the exponentially smoothing methods is naturally called "simple exponential smoothing" (SES) or "single exponential smoothing". This method is suitable for forecasting data with no trend or seasonal pattern.

Exponential Smoothing is a method that can be applied to time series data for presentation to make forecasts. The time series data themselves are a sequence of observations ${ }^{8}$. The observed occurrence may be an essentially random process, or it may be an orderly, but noisy, process. Whereas in the simple moving average, the past observations are weighted equally; Exponential smoothing assigns exponentially decreasing weights over time.

The simplest form of exponential smoothing is given by the following formula:

$F_{t+1}=\alpha A_{t}+(1-\alpha) F_{t}$

Where,

$F_{t+1}=$ Forecast for period $t+1$

$F_{t}=$ Forecast for the previous period (i.e. Period $t$ )

$\alpha=$ Smoothing constant (percentage) and $0<\alpha<1$

$A_{t}=$ Actual demand or sales for the previous period

We can interpret the new estimate of level may be seen as a weighted average of ${ }^{A_{t}}$, the most current information of average level and $F_{t}$ be the previous estimate of that level. Small values of ${ }^{\alpha}$ imply that the revision of the old forecast, in light of the new demand, is small; the new forecast is not very different from the previous one. The method requires an initial forecast $F_{1}$ which has to be either assumed or estimated.

Linear Trend. Linear Regression is used to model the relationship between a response variable and one or more predictor variables. The equation has the form, where $\mathrm{Y}$ is the dependent variable (that's the variable that goes on the $\mathrm{Y}$ axis), $\mathrm{X}$ is the independent variable (i.e. it is plotted on the $\mathrm{X}$ axis), $\mathrm{b}$ is the slope of the line and $\mathrm{a}$ is the $\mathrm{y}$-intercept.

Holt's Method. Double exponential smoothing, of which Holt's method is the most common example, can also be used to forecast when there is a linear trend present in the data. The method requires separate smoothing constants for slope and intercept. Here, the time series exhibits a trend; in addition to the level component, the trend (slope) has to be estimated. The forecast, including trend for the upcoming period, is given by

Here, is the estimate of level made at the end of period and is given by is the estimate of trend at the end of period and is given by is also a smoothing constant between 0 and 1 and plays a role similar to that of .

\section{Initialization}

The initial estimated base label is assumed from the last period observation and initial trend is the average monthly or weekly change.

Last period's observation

Average monthly or weekly increase

Where denotes an estimate of the level of the series at time denotes an estimate of the trend (slope) of the series at time $\mathrm{t}, \alpha$ is the smoothing parameter for the level, $0 \leq \alpha \leq 1$ and is the smoothing parameter for the trend, $0 \leq \beta \leq 1$. 
Winter's Method. Winters' method employs a level component, a trend component, and a seasonal component at each period. It uses three weights, or smoothing parameters, to update the components at each period. Initial values for the level and trend components are obtained from a linear regression on time. Initial values for the seasonal component are obtained from a indicator variable regression using detrended data.

Level equation

Trend equation $\mathrm{T}_{\mathrm{t}}=\gamma\left[\mathrm{L}_{\mathrm{t}}-\mathrm{L}_{\mathrm{t}-1}\right]+(1-\gamma) \mathrm{T}_{\mathrm{t}-1}$

Seasonal equation

Forecast equation $\hat{Y}_{\mathrm{t}}=\mathrm{L}_{\mathrm{t}-1}+\mathrm{T}_{\mathrm{t}-1}+\mathrm{S}_{\mathrm{t}-}$

\section{Problem Discussion and Data Collection}

Inventory control of any product is vital, as it is directly related to cost minimization and customer satisfaction. In this research, our objective is to find out a forecasting technique which is best error free to predict the future demand of white paper for printing purpose of DIU. Secondary data is used in this research and for analysis and arrangements of data, we will use Microsoft excel.

Table 1. Collected data from university store house

\begin{tabular}{|c|c|c|c|c|c|c|}
\hline Period & $\begin{array}{l}2011 \\
\text { Used } \\
\text { Printin } \\
\text { g } \\
\text { Paper( } \\
\text { rim) }\end{array}$ & $\begin{array}{l}2012 \\
\text { Used } \\
\text { Printing } \\
\text { Paper(ri } \\
\text { m) }\end{array}$ & $\begin{array}{c}2013 \\
\text { Used } \\
\text { Printi } \\
\text { ng } \\
\text { Paper } \\
\text { (rim) }\end{array}$ & $\begin{array}{c}2014 \\
\text { Used } \\
\text { Printi } \\
\text { ng } \\
\text { Paper } \\
\text { (rim) }\end{array}$ & $\begin{array}{l}2015 \\
\text { Used } \\
\text { Printi } \\
\text { ng } \\
\text { Paper } \\
\text { (rim) }\end{array}$ & $\begin{array}{c}2016 \\
\text { Used } \\
\text { Printi } \\
\text { ng } \\
\text { Paper } \\
\text { (rim) }\end{array}$ \\
\hline Spring & 697 & 761 & 961 & 1136 & 1572 & 1699 \\
\hline Summer & 686 & 675 & 972 & 1170 & 1371 & 1481 \\
\hline Fall & 731 & 688 & 1131 & 1117 & 1439 & 1781 \\
\hline
\end{tabular}

In table 1, we presented the data (demand of printing paper from January'11(spring) to December'16(fall)) that are used for the analysis of our paper.

\section{Data Analysis}

In this section, we will first show the pattern of the data against the time and then will analyze the data with the existing forecasting methods for finding errors.

Time series are often consist of one or more of the data patterns such as trend, cyclical, seasonal and horizontal component.

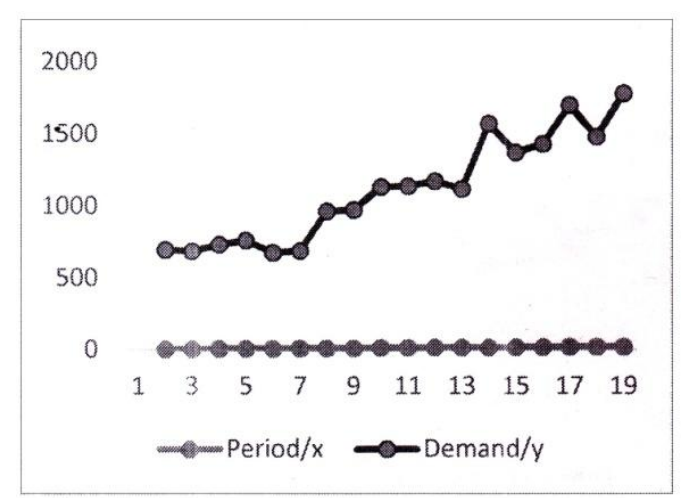

Fig. 1. Demand of printing paper from spring 2011 to fall 2016.
As from Figure 1, it shows that there was a significant growth in the time series over an extended period of time. This means that there was a trend component in the time series plot. We will analyze the data by the following eight different techniques.

\section{Time-Series Forecasting Techniques}

1. 3-point Single Moving Average (3-SMA)

2. Double Moving Average (DMA)

3. 5-point Single Moving Average (5-SMA)

4. Weighted Average (WA)

5. Exponential Smoothing (ES)

6. Linear Trend (LT)

7. Holt's Method (HM)

8. Winter's Method (WM)

\section{Single Moving Average}

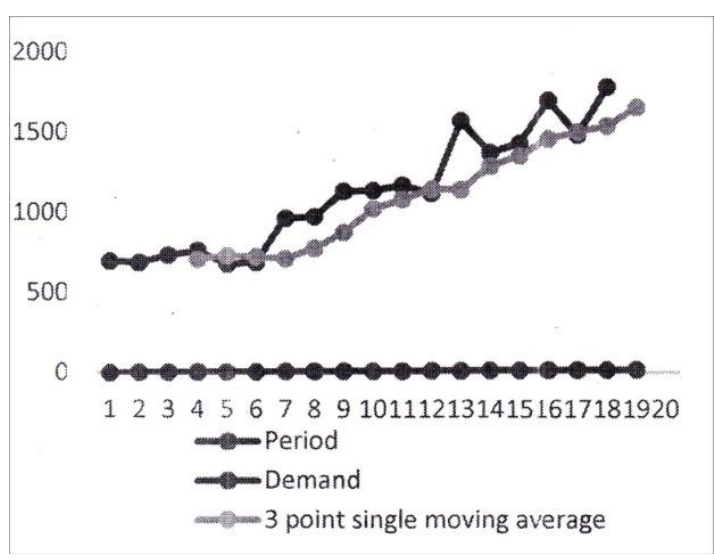

Fig. 2. Forecast using 3-SMA Technique

In figure 2, for 3-point single moving average, the demand forecast for printing paper is 1653.667 rims in spring, 2017 $(\mathrm{t}=18)$. The MAD error measurement was 135.553 , the MSE was 32244.596 where RMSE was 695.4631191 and MAPE is 11.85807571.

\section{Double Moving Average}

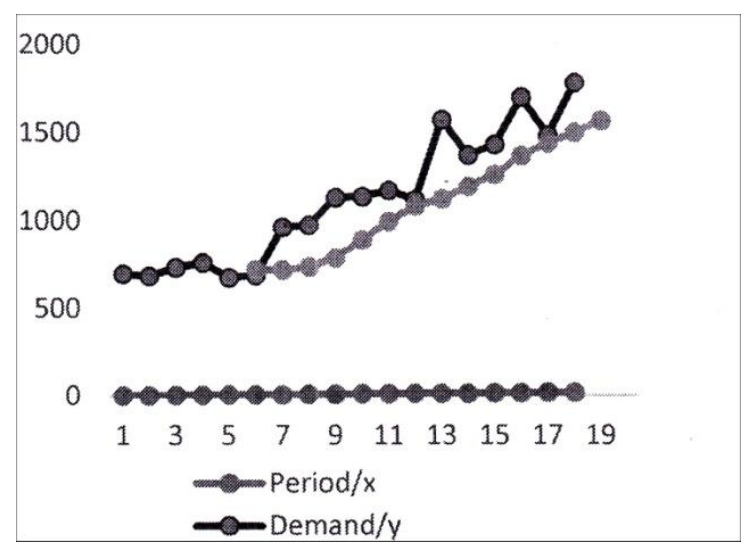

Fig. 3. Forecast using DMA Technique

In figure 3 , for double moving average, the demand forecast for printing paper is 1653.447 rims in Spring, 2017 $(\mathrm{t}=18)$ with MAD 213.3504, MSE 60413.51, RMSE 886.2142and MAPE is 16.65931 


\section{5-point Moving average}

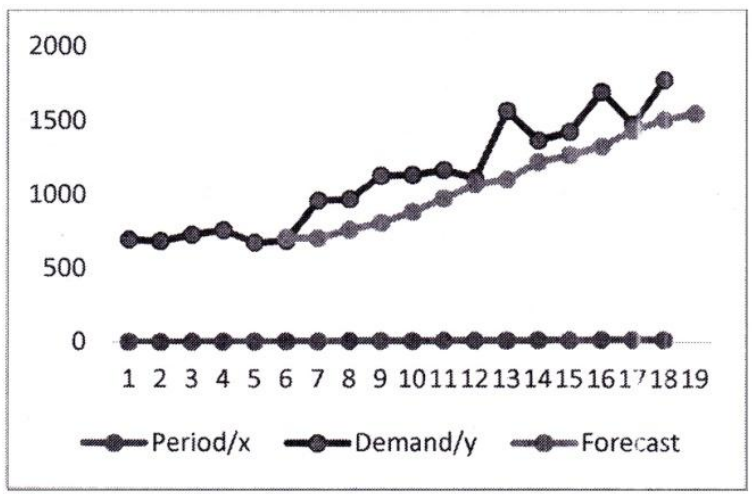

Fig. 4. Forecast using 5-point SMA Technique

In figure 4, by 5 -point moving average, the demand forecast for printing paper is 1552.4 rims in spring, $2017(\mathrm{t}=18)$. The MAD error measurement was 210.7077, the MSE was 60401.39 where RMSE was 886.1253 and MAPE is 16.3532 .

\section{Weighted Average}

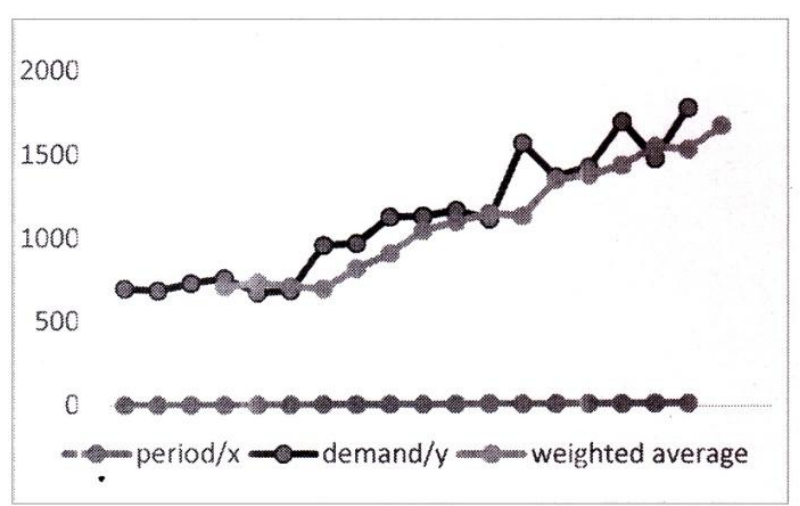

Fig. 5. Forecast using WA Technique

For weighted moving average, the demand forecast for printing paper is 1674.6 rims in Spring, 2017 ( $\mathrm{t}=18)$, which is shown in figure 5. The MAD error measurement was 136.553, the MSE was 32244.6 where RMSE was 695 and MAPE is 10.9 .

\section{Exponential Smoothing}

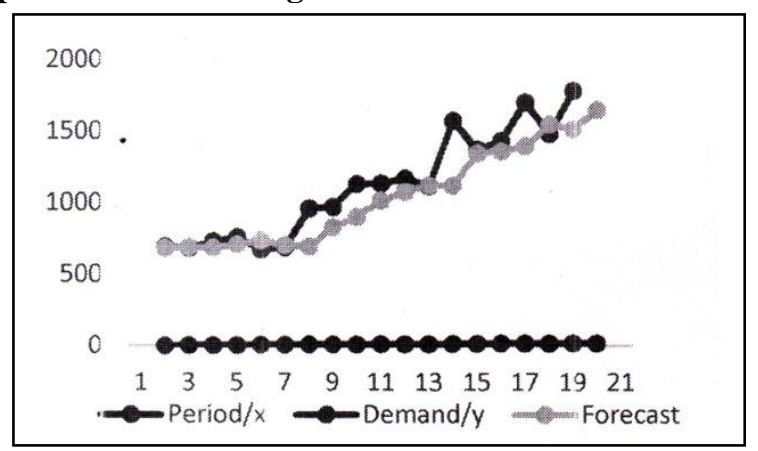

Fig. 6. Forecast using ES Technique

In figure 6, by exponential smoothing, the demand forecast for printing paper is 1647.406 rims in spring, $2017(\mathrm{t}=18)$. The MAD error measurement was 124.0122, the MSE was
30783.43 where RMSE was 744.3801and MAPE is 10.06032

\section{Linear Trend}

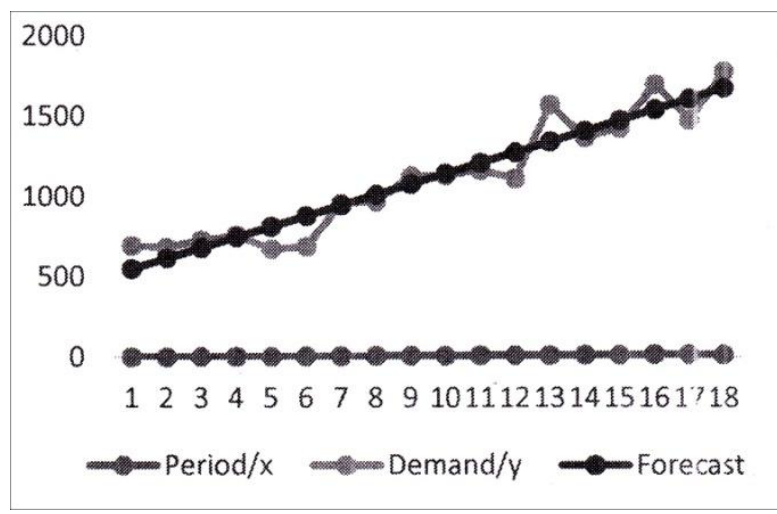

Fig 7. Forecast using LT Technique

For linear trend model, the demand forecast for printing paper is 1742.406 rims in spring, $2017(\mathrm{t}=18)$, that is shown in figure 7. The MAD error measurement was 90.73611, the MSE was 12534.05where RMSE was Figure 474.9874and MAPE is 8.979998

Holt's method

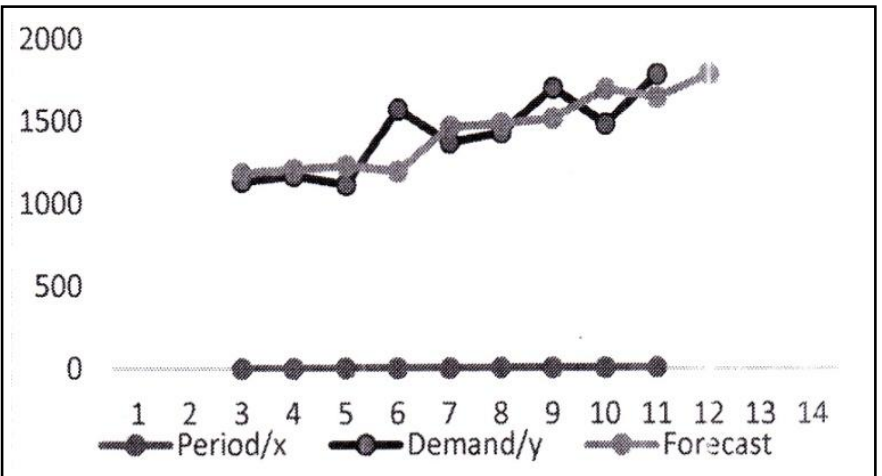

Fig. 8. Forecast using HM

In figure 8 , by Holt's method, the demand forecast for printing paper is 1785.819 rims in spring, $2017(\mathrm{t}=18)$. The MAD error measurement was 139.8205 , the MSE was 29639.33 where RMSE was 516.4823 and MAPE is 9.458981

\section{Winter's Method}

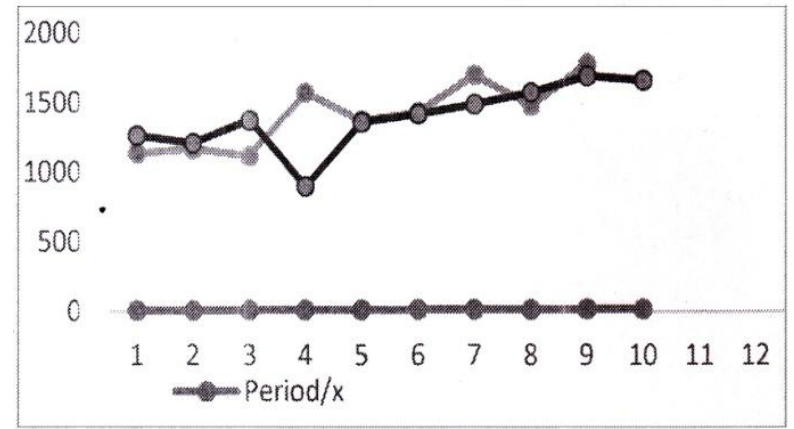

Fig 9. Forecast using Winter's Method Technique 
For Winters's method, the demand forecast for printing paper is 1663.219 rims in spring, 2017 shown in figure 9. The MAD error measurement was 168.0054, the MSE was 66413.41 where RMSE was 773.124 and MAPE is 11.74842.

\section{Comparison and Discussion}

In this section, we make a comparison table among the errors found by all types of methods.
From the research study and above table 2, linear trend technique with MAD error measurement 90.73611, MSE 12534.05, RMSE 474.9874 and MAPE 8.979998 was in first ranking as it showed the lowest of all error values. Next was Holt's method technique with second lowest RMSE 516.4823 and MAPE 9.458981. The exponential smoothing technique was in third ranking with RMSE 744.3801 and MAPE 10.06032 and so on.

Table 2. Error measurements found by eight types of forecasting methods

\begin{tabular}{|l|l|l|l|l|l|l|l|l|}
\hline $\begin{array}{l}\text { Measures } \\
\text { of Error }\end{array}$ & $\begin{array}{l}\text { Weighted } \\
\text { moving } \\
\text { Average }\end{array}$ & $\begin{array}{l}\text { 3-point } \\
\text { Single } \\
\text { Moving } \\
\text { average }\end{array}$ & $\begin{array}{l}\text { Double } \\
\text { Moving } \\
\text { Average }\end{array}$ & $\begin{array}{l}\text { 5-points } \\
\text { Moving } \\
\text { Average }\end{array}$ & $\begin{array}{l}\text { Exponential } \\
\text { Smoothing }\end{array}$ & $\begin{array}{l}\text { Linear } \\
\text { Trend } \\
\text { Analysis }\end{array}$ & $\begin{array}{l}\text { Holt's } \\
\text { Method }\end{array}$ & $\begin{array}{l}\text { Winter's } \\
\text { Method }\end{array}$ \\
\hline MAD & 136 & 135.5533 & 213.3504 & 210.7077 & 124.0122 & 90.7361 & 139.8201 & 168.0054 \\
\hline MSE & 32244.6 & 32244.596 & 60401.59 & 60401.39 & 30783.53 & 12513 & 29639.33 & 66413.41 \\
\hline RMSE & 695 & 695.4631 & 886.2142 & 886.1253 & 744.3801 & 774.9874 & 516.4823 & 773.124 \\
\hline MAPE & 10.9 & 11.85 & 16.59 & 16.3522 & 10.0603 & 8.9799 & 9.4589 & 11.7484 \\
\hline
\end{tabular}

\section{Conclusion}

In this paper, a case study was conducted using the demand data of printing papers of a university store house for last 6 years (18 trimesters), from January (Spring) 2011 to December (Fall) 2016. The purpose was to find out the best error free forecasting techniques for the demand of printing paper for a particular time period by using the time series forecasting models. According to the forecasting accuracy measurement, we observed that the best forecasting technique is linear trend equation model of all the techniques considered in this paper. One can use this technique for finding the demand of any inventory or stationary for any organization. Mathematical programming techniques such as linear programming or integer programming can be alternative options which will be studied for future research.

\section{References}

1. Bowersox D., D. Closs and M. B.Copper, 2002. Supply Chain Logistics anagement ( $4^{\text {th }}$ Edision $)$, McGraw Hill: Irwin

2. Chopra S. and P. Meindl, 2007. Supply Chain Management: Strategy, Planning, and Operation ( $3^{\text {rd }}$ Ed), Pearson Education Inc: New Jersery.

3. Kerkkanen A, 2010. Improving Demand Forecasting Practices in the Industrial Context, Lappeenranta University of Technology: Ph.D. Thesis.

4. Makridakis S., 1989. Why Combing Works?, International Journal of Forecasting, 5, 601-603.

5. Marican S., 2006. Penyelidikan Sains Social: Pendekatan Pragmatik. Kuala Lumpur: PencetakanNazSdn. Bhd.
6. Muzumdar M. and J. Fontanella, 2006. The Secrets to S \& OP Success, Supply Chain Management Review.

7. Jonsson P. and M. Gustavsson, 2009. The impact of supply chain relationships and automatic data communication and registration on forecast information quality, International Journal of Physical Distribution and Logistics Management, 38(4), 280-295.

8. Fildes R., P. Goodwin, M. Lawrence and K. Nikolopoulos, 2009. Effective forecasting and judgmental adjustments: an empirical evaluation and strategies for improvement in supply-chain planning, International Journal of Forecasting, 25(1), 3-23.

9. Ritzman I.P.and King B.E, 1993. The Relative Significance of Forecast Errors in Multistage Manufacturing, Journal of Operation Management, 11, 51-65.

10. Stock J.R. and Lambert D.M., 2001. Strategic Logistics Management (4 ${ }^{\text {th }}$ Ed), McGraw Hill Irwin: New York

11. Wacker J.G. and R.R. Lummus, 2002. Sales Forecasting For Strategic Resources Rlanning, International Journal of Operation \& Production Management, 22(9), 1014-1031

12. Wallace T.F. and R.A. Stah, 2006. Sales and Operations Planning: The Executive's Guide, Wallace \& Company: the United States of America.

13. Winklehofer H., A. Diamantopoulos, and S.F. Witt, 1996. Forecasting Practice: A Review of the Empirical Literature and an Agenda for the Future Research., International Journal of Forecasting, 12(2), 193-221. 
